\title{
Use the biometric parameters to characterize the local fig (Ficus carica $L$ ) in Tafza area of Morocco
}

\author{
El Oualkadi A*, Hajjaj B*
}

*INRA- Regional Agricultural Research Center of Tangier, Morocco

Corresponding author. E-mail: ai.oualkadi@gmail.com

\begin{abstract}
In objective to identify and characterize the richness of fig tree in limited area of northwest of morocco, abroad prospection was carried out in northwest Morocco. It included zones located in Tafza region as well as in the provinces of chefchaouen. A total of 130 accessions were sampled, studied and identified by used the biometric analyses include in European program GEN LMBO 029. As a result of the study a total of 13 different fig varieties were identified. Several synonymies and homonymies were detected. Comparison of the ecotype shows the high significatif difference, the conservation of the local cultivars is highly recommended.

Keywords-Ficus carica L, genetic resource, biometric analysis, Tafza area, Morocco.
\end{abstract}

\section{INTRODUCTION}

In Morocco, the fig tree is a tree of great importance for the Moroccan population and which fulfills several functions: social, economic and environment [1]. Among the fruit crops, the fig tree occupies the fourth place after the olive, the rosacea with pips and rosacea with. However, in the Northern region (Rif), the fig tree is one of the main agricultural resources and occupies the second place after the almond tree from the point of view of fruit plantations. The fig tree is considered in Morocco as a fruit species of secondary importance [2], [3]. However, at the regional scale and from the point of view of agrodiversity, its varietal diversity and its omnipresence designate it as one of the characteristic elements of the agro-ecosystems of the Rif Mountains [4], [5]. The study of the shape of the fruit is of paramount importance because it is according to this characteristic that one decides on the treatment to be subjected to it. The fruits are of variable shape within the same tree and during the same season [6]. To avoid this hazard, we often rely on the presence or absence of neck. Other authors rely on three dimensions of the fruit to differentiate the varieties: the length $\mathrm{C}$, the diameter $\mathrm{D}$, and the distance $\mathrm{A}$ separating the base from the center of the circle of diameter D. The first work concerning the pomological description of fig varieties has been done by Tayou in 1985 but from limited surveys to the Chefchaouen region. The evaluation of the morphological and pomological diversity of the fig tree in northern Morocco [7] showed that fig cultivars are highly diverse and provide a large collection of genotypes. However, because of many possible cases of synonymy and homonymy, the pomological characterization is insufficient for the establishment of reference genotypes of figs in Morocco. The objective of this work is the study of diversity of fig tree in the located area of the northwest of Morocco, by using the biometric analysis.

\section{MATERIAL AND METHODS}

\section{Plant material}

The plant material used in this study was constituted by the fig fruits, a total of 13 fig fruit prospected at different localities in Tafza region in Northwestern of Morocco. In total 130 accessions were gathered. In many cases, either isolated plants or plants located at old fig plantations areas were sampled. Cultivars were selected for their large distribution and their commercial value in the three regions. Samples of 130 homogenous fruits (three replicates of 10 fruits each) were chosen for each ecotype. Fruits were selected ripe and free from diseases.

\section{Approach Biometric}

A sample of ten fruits was randomly collected from different branches of the tree. The weight of the fruit was measured fruit by fruit with a precision scale in the laboratory. For these same samples, weight, of fruit, the dimensions of the fruit (length Width Height) and ostiole width were measured using a caliper (Fig. 2). The descriptors used were adapted list drawn up by European program GEN LMBO 029 [8]. The general appearance of the fruit corresponds to its external form. In this aspect, we are interested in the shape and size of the fruit. 


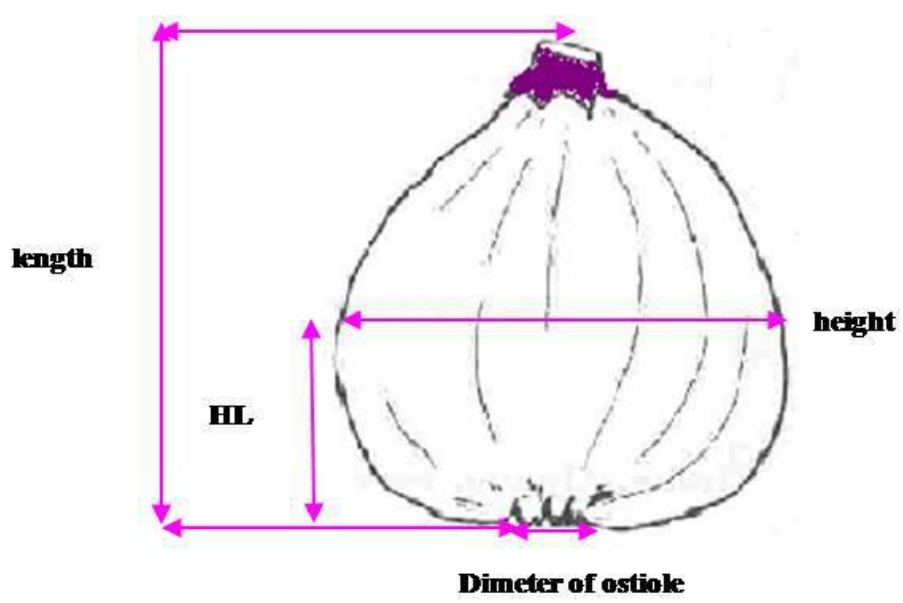

Fig.1: Representative schema of measurements made on fig fruit

\section{Statistical analysis}

Comparison between the ecotype was made possible by statistical analysis of collected data. Data were subject to one-way analysis of variance (ANOVA) and the results are given as means \pm standard deviations (SD). Statistics were performed using Statistical Package for the Social Sciences (SPSS version 13.0; SPSS Inc.).

\section{RESULTS AND DISCUSSION}

13 varieties were identified in Tafza region and 130 accessions were collected either as unidentified or with local names. As result of the biometric approach the prospected plant material was characterized.

The average weight of the varieties studied varied from $11.4 \mathrm{~g}$ to $44.22 \mathrm{~g}$ (Table 1 ). The Al chitoui variety shows the highest weight while the Hafri variety shows the lowest weight. The analysis of variance showed nine homogeneous groups from the weight fruit (Table 1).

The average length of the fruit varied between $3 \mathrm{~cm}$ and $4.7 \mathrm{~cm}$ (Table 1), the variety Al Rounbiz showed the height value of the length of the fruit whereas the varieties Al qouti and Mouslikh showed the lowest value of the length of the fruit. We distinguished eight groups significantly different from the Length of fruit (Table 1). The varieties Hafri, Al gaouzi and ounq hmam are not significantly different. The varieties Al chatoui, Kouhli and $\mathrm{Al}$ rounbiz each one formed one group significantly different to the other group (Table 1).
The width of the fruit varied between $2.8 \mathrm{~cm}$ and $4.4 \mathrm{~cm}$ (Table 1), the Hafri variety shows the weaker value of width fruit while the varieties Bakour and Lndbar shows the greatest value of the width of the fruit (Fgi.2). The analysis of variance shows five groups significantly different from the width of fruit. The varieties Ounq hmam, Assal, Al qouti, Al aroui, Larchan, Mouslikh are significantly not different for the parameter Width of fruit (Table 1).

The value of HL varied between $1.5 \mathrm{~cm}$ and $2.3 \mathrm{~cm}$ (Table 1), the varieties $\mathrm{Al}$ chatoui and Bakour shows the greatest value while the variety Hafri shows the lowest value of HL. The analysis of variance shows six groups significantly different from the parameter HL (Table 1).

The diameter of the ostiole varied between $0.1 \mathrm{~cm}$ and $0.87 \mathrm{~cm}$ (Table 1) the variety Hafri shows the smallest value of the diameter of the ostiole whereas the variety Larchan shows the greatest value of the diameter of the ostiole. The analysis of variance shows that the varieties Assal, Bakour, Al aroui and Lndbar are not significantly different (Table 1).

The length/ Width ratio of the fruit varies between 0.78 and 1.16 (Table 1), the greatest value of the length / width ratio of the fruit was observed in the Hafri variety, while the lowest value was observed in the Al qouti variety. The analysis of variance shows seven groups significantly different. The varieties Hafri, Al chitoui, Al aroui and Al rounbiz are not significantly different from the ratio Length/width (Table 1).

The length / HL of the fruit varied between 1.4 and 3.9 (Table 1), it is found that the variety Mouslikh showed the lowest value of the ratio length / HL while the variety Hafri showed the most great value. Table 1 shows three groups significantly different (Table 1).

In these results, we find that the variety $\mathrm{Al}$ chitoui (Fig.3) showed the greatest value of the weight of the fruit and the value of HL of the fruit. However the Bakour and Lndbar varieties (Fig.2) showed the greatest value of the width of the fruit; when the variety Larchan shows the greatest value of the diameter of the ostiole. 
Table 1: Biometric characteristics of fig cultivars harvested from the region

\begin{tabular}{lccccccc}
\hline Variety & Weight $(\mathrm{g})$ & $\begin{array}{c}\text { length } \\
(\mathrm{cm})\end{array}$ & width $(\mathrm{cm})$ & HI $(\mathrm{cm})$ & Diameter of ostiole $(\mathrm{cm})$ & Length/Width & Length/HL \\
\hline Hafri & $11,4 \mathrm{a}$ & $3,2 \mathrm{ab}$ & $2,8 \mathrm{a}$ & $1,5 \mathrm{a}$ & $0,1 \mathrm{a}$ & $1,16 \mathrm{ef}$ & $3,9 \mathrm{~b}$ \\
Al chitoui & $44,22 \mathrm{f}$ & $4,91 \mathrm{f}$ & $4,24 \mathrm{~d}$ & $2,3 \mathrm{e}$ & $0,43 \mathrm{bcd}$ & $1,15 \mathrm{ef}$ & $2,10 \mathrm{ab}$ \\
Al gaouizi & $13,9 \mathrm{ab}$ & $3,1 \mathrm{ab}$ & $3,1 \mathrm{ab}$ & $1,6 \mathrm{ab}$ & $0,2 \mathrm{ab}$ & $0,9 \mathrm{~cd}$ & $1,9 \mathrm{ab}$ \\
Ounq hmam & $36,33 \mathrm{def}$ & $3,21 \mathrm{ab}$ & $3,7 \mathrm{c}$ & $1,9 \mathrm{~cd}$ & $0,38 \mathrm{abc}$ & $0,8 \mathrm{ab}$ & $1,6 \mathrm{a}$ \\
Assal & $28,71 \mathrm{cde}$ & $4,5 \mathrm{de}$ & $3,7 \mathrm{c}$ & $1,98 \mathrm{~d}$ & $0,51 \mathrm{~cd}$ & $1,20 \mathrm{f}$ & $2,2 \mathrm{ab}$ \\
Bakour & $43 \mathrm{f}$ & $4 \mathrm{c}$ & $4,4 \mathrm{~d}$ & $2,3 \mathrm{e}$ & $0,5 \mathrm{~cd}$ & $0,9 \mathrm{bc}$ & $1,7 \mathrm{ab}$ \\
Al qouti & $21,7 \mathrm{abc}$ & $3,04 \mathrm{a}$ & $3,8 \mathrm{c}$ & $1,9 \mathrm{~cd}$ & $0,63 \mathrm{~d}$ & $0,78 \mathrm{a}$ & $1,5 \mathrm{a}$ \\
Al aroui & $26,7 \mathrm{bcd}$ & $4,1 \mathrm{~cd}$ & $3,6 \mathrm{c}$ & $1,9 \mathrm{~cd}$ & $0,5 \mathrm{~cd}$ & $1,13 \mathrm{ef}$ & $2,1 \mathrm{ab}$ \\
Larchan & $24 \mathrm{abcd}$ & $3,9 \mathrm{c}$ & $3,8 \mathrm{c}$ & $1,8 \mathrm{~cd}$ & $0,87 \mathrm{e}$ & $1,0 \mathrm{~cd}$ & $2,1 \mathrm{ab}$ \\
Mouslikh & $20 \mathrm{abc}$ & $3,03 \mathrm{a}$ & $3,6 \mathrm{c}$ & $1,8 \mathrm{~cd}$ & $0,61 \mathrm{~d}$ & $0,8 \mathrm{ab}$ & $1,4 \mathrm{a}$ \\
Lndbar & $34,8 \mathrm{def}$ & $4,1 \mathrm{~cd}$ & $4,4 \mathrm{~d}$ & $2,1 \mathrm{e}$ & $0,5 \mathrm{~cd}$ & $0,9 \mathrm{bc}$ & $1,8 \mathrm{ab}$ \\
kouhli & $16,8 \mathrm{abc}$ & $3,49 \mathrm{~b}$ & $3,3 \mathrm{bc}$ & $1,7 \mathrm{~b}$ & $0,2 \mathrm{a}$ & $1,05 \mathrm{de}$ & $1,97 \mathrm{ab}$ \\
Al rounbiz & $40,25 \mathrm{ef}$ & $4,72 \mathrm{ef}$ & $4,2 \mathrm{~d}$ & $2,17 \mathrm{e}$ & $0,47 \mathrm{bcd}$ & $1,12 \mathrm{ef}$ & $2,1 \mathrm{ab}$ \\
$P \alpha=0.05$ & 0 & 0 & 0 & 0 & 0 & 0 & 0
\end{tabular}

Significant differences within the same column and means followed by the same letter do not differ at $P \alpha \leq 0.05$ according to Duncan test

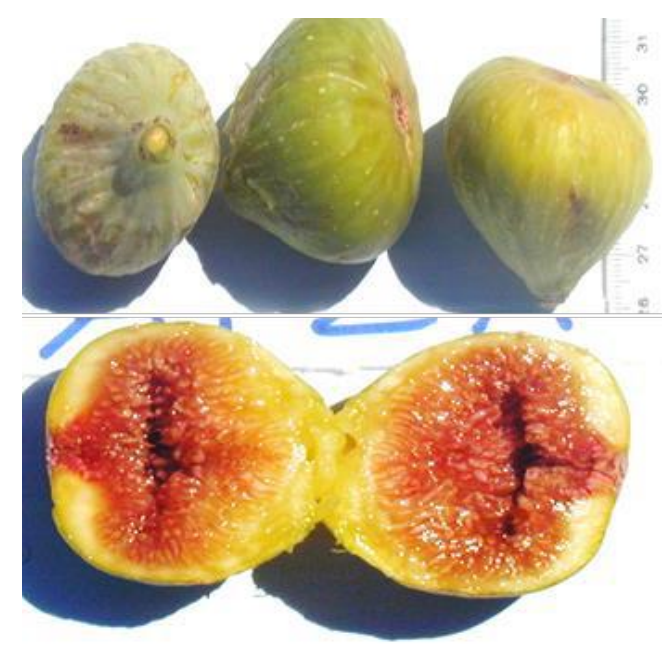

Fig.2: Fruit of variety Landbar from Tafza area

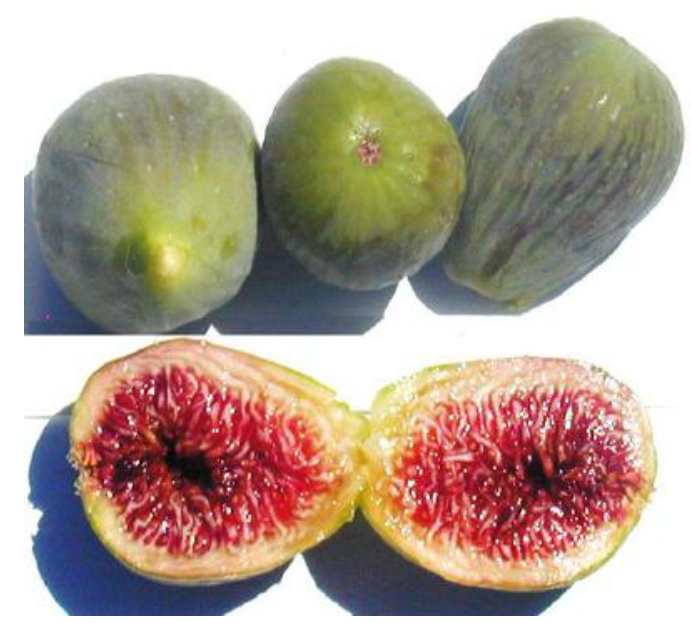

Fig 3. Fruit of variety Chitoui from Tafza area

\section{CONCLUSIONS}

In this work we have characterized and identified figs in the region of Tafza located north of Morocco. This study shows the existence of a great morphological diversity of figs in this region. Thus 13 varieties were identified and showed a great biometric diversity of the fruits. Considered as genetic resources, these varieties must be preserved in a germplasm bank for preservation.

\section{ACKNOWLEDGMENT}

The authors are grateful to all farmers in Tafza region for providing necessary facilities for conducting this research work.

\section{REFERENCES}

[1] El Bouzidi S. 2002. Le figuier: histoire, rituel et symbolisme en Afrique du Nord. Dialogues d'Histoire Ancienne 28:103-120.

[2] Walali Loudiyi D. (2002) Quelques espèces fruitières d'intérêt secondaire cultivées au Maroc. In : Llácer G., Aksoy U. \& Mars M. (Ed.) Cultures fruitières sousutilisées dans la région méditerranéenne. CIHEAM-IAMZ (Zaragoza) : 47-62.

[3] Oukabli A. (2003) Le figuier: un patrimoine génétique diversifié à exploiter. Bulletin mensuel d'information et de liaison du PNTTA 106, 4 p.

[4] Aumeeruddy-Thomas Y. (2010) Des clones aux semis : domestication des arbres en Méditerranée, un continuum entre nature et culture. Exemple de Ficus carica L., Olea europaea L. et Castanea sativa L. In Delhon C., Théry- 
Parisot I. \& Thiébault S. (dir.) Des Hommes et des plantes: Exploitation du milieu et gestion des ressources végétales de la préhistoire d'Antibes. APDCA: 379-390.

[5] Aumeeruddy-Thomas Y., Hmimsa Y., Ater M. \& Khadari B. 2014 - Beyond the divide between wild and domesticated: spatiality, domesticity and practices pertaining to fig (Ficus carica L.) and olive (Olea europaea L.) agroecosystems in Morocco. In: Chevalier A., Marinova E. \& Peña-Chocarro L. (Ed.) Crops and people: choices and diversity through time. Brussels, Earth EU, London, OXFAM: 191-197.

[6] Simonet, M., R. Chopinet, and J. Baccialone (1945) Contribution à l' etude de quelques variétés de figuiers des Alpes-Maritimes et du Var. Rev. Bot. Appl. 25:44-75.

[7] Ater M., El Oualkadi A., Achtak H., Oukabli A., Khadari B. 2008. Diversity of the local varieties of fig tree in the north-western Morocco. Acta Hort. 98:69-76.

[8] Roger, J.P (2000) Identification variétale d'une espèce méconnue: le figuier, Rapp. Interne, Conserv. Bot. Ntl., Porquerolles, France. 